\title{
ReviewPaper:Rehabilitation of Stress Urinary Incontinence: A Review Article
}

\author{
Khadijeh Otadi $^{1}$ (D, Fatemeh Sadat Hasheminasab Zavareh ${ }^{1}$
}

1. Department of Physiotherapy, Faculty of Rehabilitation, Tehran University of Medical Sciences, Tehran. Iran.

$\begin{gathered}\text { Use your device toscan } \\ \text { and read the article online }\end{gathered}$
Modern Rehabilitation. 2019; 13(3):129-136. http://dx.doi.org/10.32598/JMR.13.3.129
dolith: http:/dx.doi.org/10.32598/JMR.13.3.129

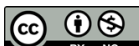

Article info:

Received: 10 Jan 2019

Accepted: 23 May 2019

Available Online: 01 Jul 2019

\section{Keywords:}

Urinary incontinence, Electrotherapy, Pelvic floor Physiotherapy (techniques), Rehabilitation, Pelvic Floor Muscle Training, Stress Urinary Incontinence, Whole Body Vibration Training, RCT, Vibration, Vibration Training

\section{A B S T R A C T}

Introduction: This review article aims at finding papers comparing conventional treatment with new interventions in females affected with Stress Urinary Incontinence (SUI). Therefore, we selected papers with exercise therapy and Electrical Stimulation (ES) compared with vibration therapy.

Materials and Methods: We searched PubMed, Scopus, Ovid, and Springer for the papers published in English and the field of human-study registered from 2009 to 2019. The articles should be about Pelvic Floor Muscle Training (PFMT), Electrical Stimulation (ES), and new intervention like vibration in the treatment of SUI.

Results: We managed to identify 1276 articles on this topic. After deleting duplicate articles, we chose 22 of them. Based on the inclusion criteria, only 7 articles were finally included in this review article. PFMT and ES are conventional treatments, but some studies have focused on the efficiency of new modalities, such as vibration in the treatment of SUI.

Discussion: Based on our review, new intervention (vibration) has superior effects over ES and PFMT in the treatment of SUI; however, ES and PFMT are the first line of therapy.

\section{Introduction}

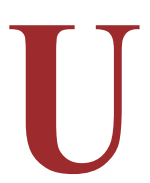

sually, aging is associated with different problems. The third most common category of problems is urologic disorders such as pelvic organ prolapsed, rectal incontinence, and urinary incontinence [1, 2]. Urinary Incontinence (UI) is the most common type of disorder (25\%-45\%) based on previous study and 2-5 times more often in women than in men. $\mathrm{UI}$ is a distressing condition with serious impacts on the physical, social, psychological, and sexual health of the patients [3, 4]. The International Continence Society has defined UI as any complaining of urine involuntary leakage. The most common type of UI is Stress Urinary Incontinence (SUI) that refers to involuntary leakage of urine when intra-abdominal pressure increases along with deficiency of the detrusor muscle contraction [3, 5-7]. Coughing repeatedly increases the intra-abdominal pressure and typically provokes SUI. This phenomenon (coughing frequently) sometimes is used as a test for the diagnosis of SUI $[8,9]$. Vaginal delivery, age, obesity,

* Corresponding Author: 
postmenopausal incontinency, chronic bronchitis and increased physical effort are some risk factors for SUI.

The SUI severity is graded based on conditions or physical activities, causing urinary leakage [10]. If SUI is associated with coughing or sneezing, it is categorized as grade I, grade II if SUI is associated with running or picking up heavy objects, and grade III, if the subject has UI while walking or climbing stairs [11]. Overactive bladder syndrome is another urinary problem characterized by urinary urgency accompany with or without urge incontinence, frequency, and nocturia $[12,13]$.

There is a wide range of treatments for urinary problems. Pharmacotherapy, surgery, and conservative interventions such as pelvic floor muscle training, lifestyle interventions, anti-incontinence devices, and absorbent products are some of the options $[14,15]$. Unfortunately, more than $50 \%$ of cases with incontinence were inadequately managed after diagnosis [16]. SUI is the most common urinary problems among other dysfunctions. Pelvic Floor Muscle (PFM) weakness is the primary and hidden cause of SUI [17]. The supportive mechanism of PFM was lost with $50 \%$ of women because of childbirth and $49 \%$ of women are unable to contract the PFM to increase the pressure and close the urethra [18].

PFM has essential functions such as supporting pelvic organs; enhancing the closure mechanism of the urethra; increasing strength, power, and improving the timing and coordination of muscle function. Therefore PFM Training (PEMT) is the first line of conservative management $[4,8]$. On the other hand, there are some novel interventions such as Whole-Body Vibration Training (WBVT) aimed at improving muscle strength, endurance, power and neuromuscular conditions.

According to previous studies, WBVT increases muscle strength [19, 20], induces muscle hypertrophy [11], improves proprioceptors [12], enlarges slow- and fasttwitch fibers, and promotes hormonal changes [10]. WBVT also improves muscle weakness, especially in patients with different chronic diseases [13-18]. Electrical Stimulation (ES) is also recommended for the treatment of patients with SUI [14-17, 21]. Acupuncture is another treatment for managing SUI with the advantage of its new version, electroacupuncture [22-24].

One systematic review was carried with the aim of assessment of PFMT efficacy on incontinency. Their results revealed the weak effects of PFMT in treating urinary incontinence in older women [25]. Another review article was carried to explain the preventive role of different physiotherapy treatments in patients with SUI. The authors concluded that the physiotherapy program should be individualized based on each patient's condition [10].

In 2017, Olivera conducted another systematic review to identify the best training parameters or protocols for the strengthening of pelvic floor muscles [26]. Based on our knowledge, there is no review study conducted about comparing these three methods (PFMT, ES, vibration) in the treatment of SUI. Our research was about the advantages or disadvantages of each treatment compared with the other two treatments.

\section{Materials and Methods}

We searched PubMed, Scopus, Ovid, and Springer for the articles published from 2009-2019 on the physiotherapy for SUI, according to the Medical Subject Heading of the National Library of Medicine (MESH). We used the keyword of "physiotherapy" in combination with "stress urinary incontinence", "pelvic floor muscle training", "electrotherapy", "electrical stimulation therapeutic", "vibration", "whole-body vibration", "rehabilitation", "women", or "female". The inclusion criteria were 1. Studies with randomized controlled design; 2. Trials that reported exclusive results on women with grade I or II of SUI; 3. and articles that method of treatment included PFMT, ES, or vibration. Studies in languages other than English were excluded. This review article is a narrative review; therefore, there was no need to choose the related high-quality evidence based on the PEDro scale.

\section{Result}

We selected 7 relevant articles and critically evaluated for checking the efficiency of Pelvic Floor Muscle Training (PFMT) and Electrical Stimulation (ES) for improving patients with SUI compared with the new intervention as vibration. PFMT and ES are the first lines of treatment, and local or whole-body vibration is a novel intervention. So few studies have been published about vibration, and further research is needed (Figure 1).

\section{Discussion}

According to our review, a few articles are about PFMT, electrical stimulation, and whole-body vibration as a novel treatment, but the available literature proves that PFMT and electrical stimulation are recommended as the first line of therapy in patients with Stress Urinary Incontinence (SUI). PFMT is a simple method, and it is recommended in patients with SUI $[7,15]$ (Table $1 \& 2$ ). 


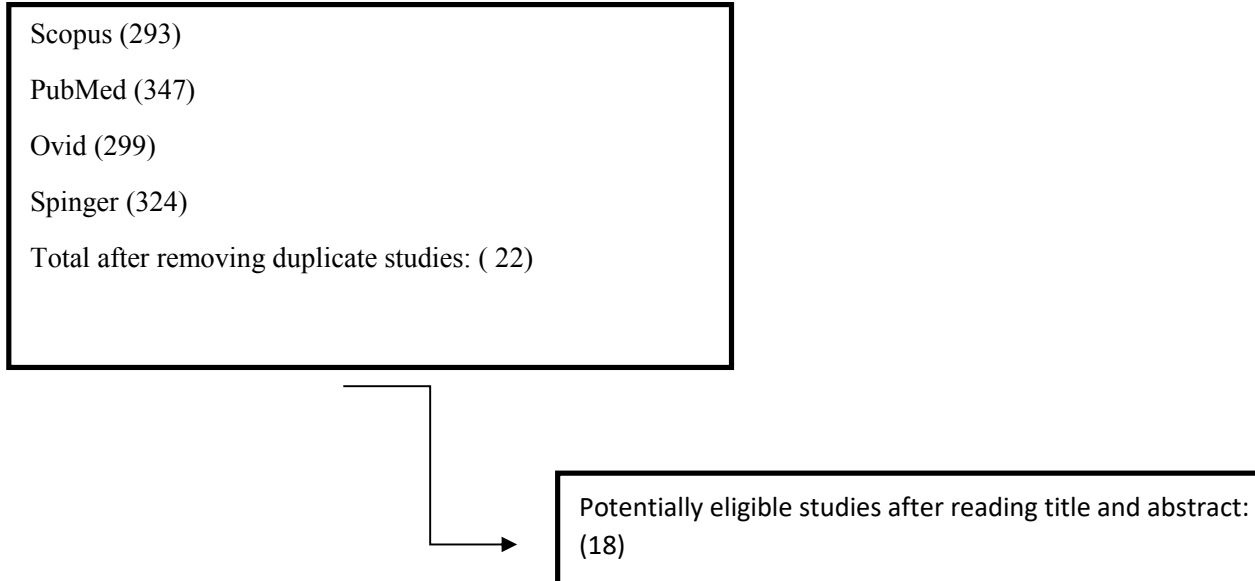

Number of articles excluded: 11

Reasons for exclusion:

- The subjects didn't have SUI (3 studies).

- Four studies did not have the control group.

- Two studies did not use study treatments.

Seven studies were included in the review.

Figure 1. Detailed flowchart demonstrating the selection process of the studies

Kargar et al. determined the efficacy of pelvic muscle training in subjects with urinary incontinency and their self-esteem. A total of 50 old females aged 60-74 years participated in that study. Each subject attended 8 training sessions [3]. The subjects filled self-esteem questionnaires and the International Consultation on Incontinence Questionnaire before and after 2 months of treatment. Quality of life and self-esteem were improved in the pelvic floor muscle training group compared with the control group [3].

Ptak M et al. (2019) compared the Pelvic Floor Muscles (PFM) exercises in isolation and combined with Transversus Abdominis ( $\operatorname{TrA}$ ) training in subjects with SUI [12]. The results demonstrated that PFM + TrA training yielded significantly better results than the (PFM) program. Also, the participants' quality of life with respect to travel, daily living activities, and sleep problems improved. Besides, fatigue decreased in these patients after training. A combination of PFM and synergistic (TrA) muscle training, the same as PFM alone, showed improvement in the quality of life. However, the combination of PFM and TrA muscle training is more effective. Therefore it seems that the combination of PFM exercise and synergistic muscle has better results in females with less childbirth than isolated PFM training [28].

After reviewing the urinary journal, we only found 3 articles investigated electrical stimulation (surface or vaginal) as a form of treatment for patients with SUI. Corriea et al. (2014) compared the efficiency of Surface Electrical Stimulation (SES) with intravaginal electrical Stimulation (IVES) in subjects with SUI. Urinary leakage, pressure, and strength of pelvic floor muscle were primary outcomes. Quality of life was evaluated by King's Health Questionnaire (KHQ) that was secondary outcomes. The patients in both groups showed significant improvement in urinary loss and the pressure of contraction. But, PFM strength increased only in the IVESG. Some differences were seen in urinary leakage between the CG and SESG and CG and IVESG.

Regarding the quality of life, there was a significant reduction in the incontinence impact, limitations of daily activities, physical limitation, emotion, sleep and disposition, and severity domains in the SESG and IVESG after the treatments [15]. Castro et al. (2008) compared the efficacy of pelvic floor muscle training, ES, vaginal cones, 
Table 1. Details of the included studies

\begin{tabular}{|c|c|c|c|c|c|c|}
\hline \multirow{2}{*}{$\begin{array}{c}\text { Study } \\
\text { (Reference) }\end{array}$} & \multirow{2}{*}{$\begin{array}{l}\text { Duration of } \\
\text { Treatment }\end{array}$} & \multicolumn{2}{|c|}{ Groups } & \multirow{2}{*}{ Age (y) } & \multirow{2}{*}{$\begin{array}{l}\text { Number of } \\
\text { Participants }\end{array}$} & \multirow{2}{*}{ Outcome Measure } \\
\hline & & Experimental & Control & & & \\
\hline $\begin{array}{l}\text { Correia et al. } \\
2014 \text { [15] }\end{array}$ & $\begin{array}{l}12 \text { sessions } \\
\text { Two weekly ses- } \\
\text { sions for } \\
20 \text { min }\end{array}$ & $\begin{array}{l}\text { SESG }(n=15) \\
\text { IVES }(n=15)\end{array}$ & $\begin{array}{l}\text { No interven- } \\
\text { tion } \\
(n=15)\end{array}$ & $>50$ & $n=48$ & $\begin{array}{c}\text { Urinary leakage } \\
\text { pressure \& strength of Pelvic } \\
\text { Floor Muscle (PFM), Quality } \\
\text { of Life (QOL) } \\
\text { Time of leakage urine } \\
\text { Total scores of questions of } \\
\text { King's Health Questionnaire } \\
\text { (KHQ) }\end{array}$ \\
\hline $\begin{array}{l}\text { Kargar et al. } \\
2013 \text { [3] }\end{array}$ & $\begin{array}{c}8 \text { sessions } \\
\text { once a week for } \\
45 \mathrm{~min}\end{array}$ & $\begin{array}{l}\text { Kegel exercise } \\
\quad(n=25)\end{array}$ & $\begin{array}{l}\text { No interven- } \\
\text { tion } \\
(n=25)\end{array}$ & $60-74$ & $n=50$ & $\begin{array}{c}\text { Frequencies of urine leakage, } \\
\text { amount of urine leakage, } \\
\text { QOL, } \\
\text { time of urine leakage }\end{array}$ \\
\hline $\begin{array}{l}\text { Castro et al. } \\
2008 \text { [27] }\end{array}$ & $\begin{array}{l}\text { Three times a } \\
\text { week, } \\
\text { 6-month trial } \\
\text { period }\end{array}$ & $\begin{array}{l}\text { Thirty subjects } \\
\text { in Electrical } \\
\text { Stimulation (ES) } \\
\text { group and } 27 \\
\text { subjects in } \\
\text { stimulation with } \\
\text { vaginal cones }\end{array}$ & $\begin{array}{c}\text { No interven- } \\
\text { tion } \\
(n=30)\end{array}$ & $52-56$ & $n=118$ & $\begin{array}{l}\text { Objective cure of stress } \\
\text { incontinence, } \\
\text { QOL }\end{array}$ \\
\hline $\begin{array}{l}\text { Stania et al. } \\
2015 \text { [28] }\end{array}$ & $\begin{array}{l}\text { Twelve weeks } \\
\text { and in each } \\
\text { week } 4 \text { sessions }\end{array}$ & $\begin{array}{l}\text { Whole-body vi- } \\
\text { bration therapy } \\
\text { (WBVT) }(\mathrm{n}=12) \\
2 \mathrm{~mm} / 20 \mathrm{~Hz} \\
\text { WBVT }(\mathrm{n}=12) \\
4 \mathrm{~mm} / 40 \mathrm{~Hz}\end{array}$ & $\begin{array}{l}\text { Exercise } \\
\text { without the } \\
\text { application } \\
\text { of vibration } \\
\quad(n=12)\end{array}$ & $21-23$ & $n=36$ & Activity of PFM \\
\hline $\begin{array}{l}\text { Farzinmehr et } \\
\text { al, } 2015 \text { [29] }\end{array}$ & $\begin{array}{l}\text { Four-week } \\
\text { training program } \\
\text { (three days per } \\
\text { week) }\end{array}$ & WBVT $(n=22)$ & $\begin{array}{l}\text { Pelvic floor } \\
\text { muscle ther- } \\
\text { apy (PFMT) } \\
(n=24)\end{array}$ & $36-68$ & $n=43$ & $\begin{array}{c}\text { PFM strength, } \\
\text { QOL, } \\
\text { incontinence intensity }\end{array}$ \\
\hline $\begin{array}{l}\text { Ong et al. } 2015 \\
\qquad \text { [30] }\end{array}$ & Sixteen weeks & $\begin{array}{l}\text { VKD } \\
\text { (PFMEs with } \\
\text { VKD biofeed- } \\
\text { back) } \\
(n=21)\end{array}$ & $\begin{array}{l}\text { PFMT } \\
(n=19)\end{array}$ & $>18$ & $n=40$ & $\begin{array}{l}\text { Stress Urinary Incontinence } \\
\text { (SUI) score } \\
\text { Total urinary score in PFM } \\
\text { strength } \\
\text { Score in social life }\end{array}$ \\
\hline $\begin{array}{l}\text { Rodrigues et } \\
\text { al. } 2019 \text { [31] }\end{array}$ & $\begin{array}{l}\text { Once a week } \\
\text { 20-minute ses- } \\
\text { sions } \\
\text { for } 6 \text { weeks }\end{array}$ & $\begin{array}{l}\text { IVVS }(n=21) \\
\text { IVES }(n=21)\end{array}$ & - & $>18$ & $n=42$ & PFM strength \\
\hline
\end{tabular}

$J \mathrm{MR}$

SESG: Surface electrical stimulation group; IVES: Intravaginal electrical stimulation; PFM: Pelvic floor muscle; QoL: Quality of life, KHQ: King's Health Questionnaire; ES: electrical stimulation; WBVT: Whole-body vibration training; PFMT: Pelvic floor muscle therapy; VKD: Vibration kegel devise; SUI: Stress urinary incontinence; IVVS: Intravaginal vibration devises; IVES: Intravaginal electrical stimulation.

with the control in SUI females with the urodynamic test, pad test, and Quality of Life Questionnaire (I-QOL) [27].

The results showed a significant reduction in the pad test, in episodes of stress urinary, and considerable im- provement in the quality of life in subjects who used pelvic floor exercises, electrical stimulation, and vaginal cones compared with the control group. The rate of satisfaction after treatment was 58\%, 55\%, and 54\%, respectively, in pelvic floor exercises, electrical stimu- 
Table 2. Studies that remark three interventions of SUI

\begin{tabular}{|c|c|c|c|}
\hline Study & Study Design & Methodological Quality & Remarks \\
\hline $\begin{array}{l}\text { Correia et al. } \\
2014 \text { [15] }\end{array}$ & $\begin{array}{l}\text { Randomized } \\
\text { controlled trial }\end{array}$ & $\begin{array}{c}\text { One blinded experienced physiotherapist per- } \\
\text { formed all evaluations } \\
\text { limitations were the absence of an EMG and ultra- } \\
\text { sonography assessment }\end{array}$ & $\begin{array}{l}\text { SES and IVES had a positive effect on } \\
\text { the subjects with SUI. } \\
\text { SES is a good option in patients with } \\
\text { SUI and had many advantages. }\end{array}$ \\
\hline $\begin{array}{c}\text { Kargar et al. } \\
2013[3]\end{array}$ & $\begin{array}{l}\text { Randomized } \\
\text { controlled trial }\end{array}$ & $\begin{array}{c}\text { Use } 3 \text { questionnaires } \\
\text { The limitation is recognizing kegel exercise correctly } \\
\text { and do right and not considering important points } \\
\text { about lifestyle situation }\end{array}$ & $\begin{array}{l}\text { Behavioral interventions significantly } \\
\text { improve urinary incontinence. } \\
\text { Significant effect on patients with } \\
\text { incontinence }\end{array}$ \\
\hline $\begin{array}{l}\text { Castro et al. } \\
2008[27]\end{array}$ & $\begin{array}{l}\text { Randomized } \\
\text { controlled trial }\end{array}$ & Single blinding & $\begin{array}{l}\text { PFMT group showed significantly } \\
\text { more significant improvement com- } \\
\text { pared with ES and VC. } \\
\text { PFMT should be suggested as the } \\
\text { first choice of treatment. }\end{array}$ \\
\hline $\begin{array}{l}\text { Stania et al. } 2015 \\
\text { [28] }\end{array}$ & $\begin{array}{l}\text { Randomized } \\
\text { controlled study }\end{array}$ & $\begin{array}{c}\text { A randomized, controlled, } 3 \text { parallel-group study } \\
\text { used surface electromyography to } \\
\text { assess pelvic floor muscles function in } \\
\text { real time }\end{array}$ & $\begin{array}{l}\text { Failure to find consistent guidelines } \\
\text { for WBV parameters }\end{array}$ \\
\hline $\begin{array}{l}\text { Farzinmehr et al. } \\
\qquad 2015 \text { [29] }\end{array}$ & $\begin{array}{l}\text { Randomized } \\
\text { clinical trial }\end{array}$ & - & $\begin{array}{l}\text { WBVT had similar effects in subjects } \\
\text { with pelvic floor muscle training. } \\
\text { WBVT may be an effective method in } \\
\text { SUI management. }\end{array}$ \\
\hline $\begin{array}{l}\text { Ong et al. } 2015 \\
\text { [30] }\end{array}$ & $\begin{array}{l}\text { Randomized } \\
\text { controlled pilot } \\
\text { study }\end{array}$ & No blinded & $\begin{array}{l}\text { The VKD was useful in the strength- } \\
\text { ening of pelvic floor muscles }\end{array}$ \\
\hline $\begin{array}{l}\text { Rodrigues et al. } \\
\quad 2019 \text { [31] }\end{array}$ & $\begin{array}{l}\text { Randomized } \\
\text { clinical trial }\end{array}$ & $\begin{array}{l}\text { The sample size was very small } \\
\text { and it is better to consider the results preliminary, } \\
\text { and another study with longer duration or more } \\
\text { repetitions are needed. }\end{array}$ & $\begin{array}{l}\text { IVVS was statistically better than IVES } \\
\text { in increasing of PFM strength } \\
\text { IVVS have an essential role in the } \\
\text { identification and improvement func- } \\
\text { tion of PFM. } \\
\text { vibratory stimulation is a novel } \\
\text { method with few studies }\end{array}$ \\
\hline
\end{tabular}

EMG: Electromyography; PFM: Pelvic floor muscle; SES: Surface electrical stimulation; IVES: Intravaginal electrical stimulation; SUI: Stress urinary incontinence; PFMT: Pelvic floor muscle therapy; VC: Vaginal cones; WBV: Whole-body vibration; WBVT: whole-body vibration training; VKD: Vaginal kegel devise; IVVS: Intravaginal vibration stimulation.

lation, and vaginal cones group. The authors concluded three methods have similar effects and are far superior to no treatment [27].

Based on our review of articles, there are different designs, such as PFMT alone or in combination with the strengthening of synergistic muscles or electrical stimulation. But our results showed that ES is another common and essential modality for subjects with SUI [7].

We found only one article that used WBVT for strengthening of pelvic floor muscles in subjects with SUI. Farzinmehr et al. were randomly assigned 43 women with SUI in two groups: WBVT and PFMT, with interventions for four weeks. The strength of pelvic floor muscles, quality of life, and incontinence intensity of the subject's pre- and post-intervention and
3 months later were evaluated. The authors concluded that WBVT protocol was effective in increasing pelvic floor muscle strength and I-QOL questionnaire_scores and also in reducing the severity of incontinence similar to PFMT [29].

The other study was conducted by Rodrigues et al. to compare local Intravaginal Vibratory Stimulation (IVVS) versus Intravaginal Electrical Stimulation (IVES) in women with pelvic floor dysfunctions. Both techniques have positive effects, but IVVS was significantly superior to IVES in improving pelvic floor muscle strength [31].

Therefore whole-body vibration or local vibration is recommended as a new intervention for the strengthening of pelvic floor muscle in patients with SUI. 
Only one study was done by Ong (2015) with using of new biofeedback Vibrance Kegel Device (VKD), compared with the PFME alone in subjects with SUI [30]. The patients were randomly assigned into two groups: control (PFME alone) and VKD (PFME with VKD biofeedback). The patients performed 16 weeks of pelvic floor training. Then, at weeks 0,4 , and 16, the subjects were assessed by the Australian pelvic floor questionnaire and modified Oxford scales for PFM strength. The VKD group reported significantly earlier improvement in SUI scores at week 4. However, there was no significant difference between the groups' SUI scores at week 16. The rate of strength in the pelvic floor muscle was significantly better in the VKD group at week 4 and week 16. The subjective cure rate was similar in both groups at week 16 . Therefore, VKD resulted in the early improvement in SUI scores, and the strength of pelvic muscle was improved significantly at the end of the study. The VKD has been proved useful as an adjunct for pelvic floor training [30].

Based on our results and despite methodological differences, PFMT and electrical stimulation are the first line of treatment, and vibratory stimulation as a new treatment is used infrequently but it is recommended in pelvic floor muscle training in subjects with SUI [32]. Therefore, further studies are needed to evaluate the efficacy of whole-body vibration or local vibration using alone or combined with other modalities in regards to clarification of the best methods and modality in the treatment of patients with SUI.

\section{Conclusion}

This review revealed that ES and PFMT are standard, conventional, and the first line of treatment in patients with SUI. Vibration is a promising novel treatment, but a few studies have been conducted about the efficacy of vibration as a local or general vibration. Therefore data to explain the physiological effects of vibration on these muscles are scarce. Further randomized clinical trials with different protocols, longer duration and larger samples are needed to assess the efficacy of vibration on the function of pelvic floor muscles.

\section{Ethical Considerations}

\section{Compliance with ethical guidelines}

All ethical principles were considered in this article. The participants were informed about the purpose of the research and its implementation stages; they were also assured about the confidentiality of their information; Moreover, They were allowed to leave the study whenever they wish, and if desired, the results of the research would be available to them.

\section{Funding}

This research did not receive any specific grant from funding agencies in the public, commercial, or not-for-profit sectors.

\section{Authors contributions}

Data gathering, writing- original drafts: Fatemeh Sadat Hasheminasab Zavareh, Khadijeh Otadi; Review and editing, visualization, supervision: Fatemeh Sadat Hasheminasab Zavareh.

\section{Conflict of interest}

The authors declared no conflict of interest.

\section{References}

[1] Khalil Ibrahim I, Mowafaa M, Engy M, Enas M, Mervat Sheta A Efficacy of biofeedback-assisted pelvic floor muscle training in females with pelvic floor dysfunction. Alexandria Journal of Medicine. 2015; 51(2):137-42 [DOI:10.1016/j.ajme.2014.06.001]

[2] Toledo D, Dedicaçao A, Salina Saldanha M,Haddad H, Driusso P. Physical therapy treatment in incontinent women provided by a Public Health Service. 2011; 24(2):327-35. [DOI:10.1590/S010351502011000200014]

[3] Kargar Jahromi M, Talebizadeh M, Mirzaei M. The effect of pelvic muscle exercises on urinary incontinency and self-esteem o elderly females with stress urinary incontinency .Global Journal of Health Science. 2013; 7(2):71-9. [DOI:10.5539/gihs.v7n2p71] [PMCID]

[4] Faiena I, Patel N, Jaspreet SP, Calabrese M, Tunuguntla H. Conservative management of urinary incontinence in women. Reviews in Urology. 2015; 17(3):129-39. [PMID] [PMCID]

[5] Nystrom E, Asklund M, Stenlund H, Samuelsson E. Treatment of stress urinary incontinence with a mobile app. International Urogynecology Journal. 2018; 29(9):1325-33. [DOI:10.1007/s00192 017-3514-1] [PMID] [PMCID]

[6] McLean L, Varette K, Gentilcore-Saulnier E. Pelvic floor muscle training in women with stress urinary incontinence causes hypertrophy of the urethral sphincters and reduces bladder neck mobility during coughing. Neurourology and Urodynamics. 2013; 32(8):1096-102. [DOI:10.1002/nau.22343] [PMID] [PMCID]

[7] He Q, Xiao K, Peng L, Lai J, Li H, Luo D, et al. An effective meta-analysis of magnetic stimulation therapy for urinary incontinence. Scientific Reports. 2019; 9(1):1-0. [DOI:10.1038/ s41598-019-45330-9] 
[8] Titman S. Self-management in women with stress incontinence: Strategies, outcomes and integration into clinical care. Journal of Urology. 2019; 11:111-21. [DOI:10.2147/RRU.S177826] [PMID] [PMCID]

[9] Luginbuehl H, Baeyens J, Kuhn CA, Christen R, Oberli B, Eichelberger $\mathrm{P}$, et al. Pelvic floor muscle reflex activity during coughing: An exploratory and reliability study. Annals of Physical and Rehabilitation Medicine. 2016; 59(5-6):302-7. [DOI:10.1016/j.rehab.2016.04.005] [PMID]

[10] Ghaderi F, Oskouei A. Physiotherapy for women with stress urinary incontinence. 2014; 26(9):1493-9. [DOI:10.1589/jpts.26.1493] [PMID] [PMCID]

[11] Vanessa S, Grasi C, Patricia D. Individual and group pelvic floor muscle training versus no treatment in female stress urinary incontinence. European Journal of Obstetrics \& Gynecology and Reproductive Biology. 2011; 159(2):465-71 [DOI:10.1016/j. ejogrb.2011.09.003] [PMID]

[12] Ptak M, Sylwester C, Agnieszka B, Starczewski A, Nawrocka-Rutkowska J, Diaz-Mohedo E, et al. The effect of pelvic floor muscles exercise on quality of life in women with stress urinary incontinence and its relationship with vaginal deliveries. BioMed Research International. 2019; 2019:5321864. [DOI:10.1155/2019/5321864] [PMID] [PMCID]

[13] Shahali SH, Kashanian M, Azari A, Salehi R. Effects of pelvic floor muscle exercises on quality of life outcomes in women with stress urinary incontinence. Medical Journal of the Islamic Republic of Iran. 2010; 24(3):159-62.

[14] Fitz F, Sartori M, Girão MJ, Castro R. Pelvic floor muscle training for overactive bladder symptoms: A prospective study. Revista da Associação Médica Brasileira. 2017; 63(12):1032-8. [DOI:10.1590/1806-9282.63.12.1032] [PMID]

[15] Correia G, Pereira S, Humberto S, Hirakawa P. Effects of surface and intravaginal electrical stimulation in the treatment of women with stress urinary incontinence. European Journal of Obstetrics \& Gynecology and Reproductive Biology. 2014; 173:113-8 [DOI:10.1016/j.ejogrb.2013.11.023] [PMID]

[16] Henriques Jacomo R, Fani Fitz F, Teixeira Alves A, Silveira Fernandes I, Amatuzzi Teixeira F. The effect of pelvic floor muscle training in urinary incontinent elderly women: A systematic review. Fisioterapia em Movimento. 2014; 27(4):675-89. [DOI:10.1590/0103-5150.027.004.AR02]

[17] Vecchioli Scaldazza C, Morosetti C, Giampieretti R, Lorenzetti R, Baroni M. Percutaneous tibial nerve stimulation versus electrical stimulation with pelvic floor muscle training for overactive bladder syndrome in women. International Brazilian Journal of Urology. 2017; 43(1):121-6. [DOI:10.1590/s1677-5538. ibju.2015.0719] [PMID] [PMCID]

[18] Abrams P, Cardozo L, Fall M, Griffiths D, Rosier P, Ulmsten $\mathrm{U}$, et al. The standardisation of terminology of lower urinary tract function: Report from the standardisation sub-committee of the international continence society. Neurourology and Urodynamics. 2002; 21(2):167-78. [DOI:10.1002/nau.10052] [PMID]

[19] Irwin DE, Milsom I, Chancellor MB, Kopp Z, Guan Z. Dynamic progression of overactive bladder and urinary incontinence symptoms: A systematic review. European Urology. 2010; 58(4):532-43. [DOI:10.1016/j.eururo.2010.06.007] [PMID]

[20] Vecchioli-Scaldazza C, Morosetti C, Berouz A, Giannubilo W, Ferrara V. Solifenacin succinate versus percutaneous tibial nervestimulation in women with overactive bladder syndrome: Results of a randomized controlled crossover study. Gynecologic and $\mathrm{Ob}-$ stetric Investigation. 2013; 75(4):230-4. [DOI:10.1159/000350216] [PMID]

[21] Preyer O, Umek W, Laml T, Bjelic-Radisic V, Gabriel B, Mittlboeck $M$, et al. Percutaneous tibial nerve stimulation versus tolterodine for overactive bladder in women: A randomised controlled trial. European Journal of Obstetrics \& Gynecology and Reproductive Biology. 2015; 191:51-6. [DOI:10.1016/j.ejogrb.2015.05.014] [PMID]

[22] Mo Q, Liu Z. Analysis of female stress urinary incontinence with treatment of acupuncture and moxibustion. Shanghai Journal of Acupuncture and Moxibustion. 2013; 12(5):12-20.

[23] Wang Y, Zhisun L, Peng W, Zhao J, Liu B. Acupuncture for stress urinary incontinence in adults. Cochrane Database of Systematic Reviews. 2013; 7:CD009408.. [DOI:10.1002/14651858. CD009408.pub2]

[24] Su T, Zhou J, Liu Z, Chen Y, Zhang W, Chu H, et al. The efficacy of electroacupuncture for the treatment of simple female stress urinary incontinence-comparison with pelvic floor muscle training: Study protocol for a multicenter randomized controlled trial. Trials. 2015; 16(1):45. [DOI:10.1186/s13063-015-0560-1] [PMID] [PMCID]

[25] Jácomo RH, Fitz FF, Alves AT, Fernandes IS, Teixeira FA, Sousa JB. The effect of pelvic floor muscle training in urinary incontinent elderly women: A sistematic review. Fisioterapia em Movimento. 2014; 27(4):675-89. [DOI:10.1590/0103-5150.027.004.AR02]

[26] Oliveira M, Ferreira M, Azevedo MJ, Firmino-Machado J, Santos PC. Pelvic floor muscle training protocol for stress urinary incontinence in women: A systematic review. Revista da Associação Médica Brasileira. 2017; 63(7):642-50. [DOI:10.1590/18069282.63.07.642] [PMID]

[27] Castro RA, Arruda RM, Zanetti MR, Santos PD, Sartori MG Girão MJ. Single-blind, randomized, controlled trial of pelvic floor muscle training, electrical stimulation, vaginal cones, and no active treatment in the management of stress urinary incontinence. Clinics. 2008; 63(4):465-72. [DOI:10.1590/S1807-59322008000400009]

[28] Stania M, Chmielewska D, Kwaśna K, Smykla A, Taradaj T, Juras G. Bioelectrical activity of the pelvic floor muscles during synchronous whole-body Vibration. BMC Urology. 2015; 15:107. [DOI:10.1186/s12894-015-0103-9] [PMID] [PMCID]

[29] Farzinmehr A, Moezy A, Koohpayehzadeh J, Kashanian M. A comparative study of whole body vibration training and pelvic floor muscle training on women's stress urinary incontinence. Journal of Family and Reproductive Health. 2015; 9(4):147-54 [PMID] [PMCID]

[30] Ong TA, Khong S, Keng L, Swire Ting J, Norlia Kl, Wei Sien $Y$, et al. Using the vibrance Kegel device with pelvic floor muscle exercise for stress urinary incontinence. Journal of urology. 2015; 86(3):487-91. [DOI:10.1016/j.urology.2015.06.022] [PMID]

[31] Rodrigues MP, Barbosa LJ, Paiva LL, Mallmann S, Sanches PR, Ferreira $\mathrm{CF}$, et al. Effect of intravaginal vibratory versus electric stimulation on the pelvic floor muscles: A randomized clinical trial. European Journal of Obstetrics \& Gynecology and Reproductive Biology: X. 2019; 3:100022. [DOI:10.1016/j.eurox.2019.100022] [PMID] [PMCID]

[32] Broome BA. The impact of urinary incontinence on self-efficacy and quality of life. Health and Quality of Life Outcomes. 2003; 1(1):35. [PMID] [PMCID] 
This Page Intentionally Left Blank 